\title{
O direito à cidade e os movimentos sociais: o movimento \#OcupeEstelita e a materialização da utopia
}

\author{
The right to the city and social movements: the movement \#OcupeEstelita and \\ the utopia materialization
}

\author{
Luan Guilherme Dias* \\ Juvêncio Borges Silva**
}

\begin{abstract}
A utopia está lá no horizonte. Me aproximo dois passos, ela se afasta dois passos. Caminho dez passos e o horizonte corre dez passos. Por mais que eu caminhe, jamais o alcançarei.

Para que serve a utopia? Serve para isto: para que eu não deixe de caminhar.

(Eduardo Galeano, citando Fernando Birri)
\end{abstract}

\section{Resumo}

O presente estudo tem por objetivo analisar o conceito de direito à cidade e o significado de sua apropriação pelos movimentos sociais na contemporaneidade a fim de compreender a atuação do Movimento \#OcupeEstelita na cidade de Recife-PE. Em meio ao caos das grandes cidades, que adotam o modelo desenvolvimentista como o único possível, as concepções de Henry Lefebvre renascem e ganham vida com a ação coletiva dos movimentos sociais, a partir de atos contestatórios que buscam a transformação do espaço urbano em local de convivência, descoberta e sociabilidade. A pesquisa realizada, conjugando o método dedutivo com o indutivo, a partir da análise de dados qualitativos, de natureza bibliográfica e documental, permite concluir que a utilização do conceito de direito à cidade pelos movimentos sociais possibilita o florescimento de uma nova realidade urbana, centrada no bem-estar coletivo das pessoas, como demonstra o Movimento \#OcupeEstelita, que materializa o direito à cidade na capital de Pernambuco.

Palavras-chave: Direito à cidade. Movimentos Sociais. Protestos urbanos. Henry Lefebvre.

\section{Abstract}

The present study aims to analyze the concept of the right to the city and the meaning of its appropriation by social movements in the contemporaneity, in order to understand the performance of the moviment \#OcupeEstelita, in the city of Recife-PE. In the chaos of the big cities, which adopt the developmentist model as the only possible, Henry Lefebvre's conceptions are revived and brought to life by the collective action of social movements, based on contestatory acts, seeking the transformation of urban space in place of coexistence, discovery and sociability. The research carried out, combining the deductive and the inductive method, based on the analysis of qualitative data, of a bibliographical and documentary nature, allows us to conclude that the use of the concept of the right to the city by social movements allows the blossoming of a new urban reality, centered in the collective well-being of people, as demonstrated by the movement \#OcupeEstelita, which materializes the right to the city in the capital of Pernambuco.

Keywords: Right to the city. Social movements. Urban protests. Henry Lefebvre.

\footnotetext{
* Mestrando em Direitos Coletivos e Cidadania pela Universidade de Ribeirão Preto (Unaerp), com bolsa pela Coordenação de Aperfeiçoamento de Pessoal de Nível Superior (Capes). Graduado em Direito pela Universidade de Ribeirão Preto (Unaerp). Ribeirão Preto -SP -Brasil. E-mail: luanguilhermedias@hotmail.com.

** Pós-doutorado em Direito pela Faculdade de Direito da Universidade de Coimbra. Doutor em Sociologia pela Universidade Estadual Júlio de Mesquita Filho (Unesp). Mestre em Sociologia pela Universidade de Campinas (Unicamp). Especialização em Didática e Planejamento do Ensino Superior pela Faculdade de Filosofia de Passos (Fafipa). Ribeirão Preto - SP - Brasil. E-mail: jsilva@unaerp.br.
} 


\section{Introdução}

A investigação histórica das cidades revela a transformação de suas características ao longo do tempo, com mudanças significativas e que marcaram época, sendo impossível contar a história da civilização humana sem uma prévia análise de seu desenvolvimento. Compreender o atual panorama político e buscar novas perspectivas para a vida em sociedade, do mesmo modo, demanda a compreensão sobre os limites e possibilidades da cidade.

Nos tempos atuais, regulado pela concepção mercadológica que pauta o urbanismo, a configuração das cidades mostra a sua face perversa, excluindo pessoas e gerando cisões no próprio tecido social. Urge, portanto, criar uma nova concepção de cidade, entendendo-a como espaço de encontro e descoberta, de modo a privilegiar a plena realização e a sociabilidade entre os cidadãos no espaço urbano.

Assim, ganham força novamente as concepções de Henry Lefebvre, que cunhou o termo "direito à cidade". Renovado para atender às demandas de nossa época, o conceito é potencializado e ganha ares emancipatórios quando aliado à atuação dos movimentos sociais. Nesse sentido, destaca-se o Movimento \#OcupeEstelita, da cidade de Recife, que busca a reconfiguração do espaço na capital pernambucana, priorizando as pessoas.

O presente estudo, dentro desse conturbado contexto, faz uso de dados qualitativos, de natureza bibliográfica e documental, e analisa a obra de diversos autores das áreas do direito e da sociologia, conjugando o método dedutivo com o indutivo, e tem por objetivo contribuir com o debate sobre os movimentos sociais urbanos na contemporaneidade, bem como sobre a atualidade do direito à cidade, na tentativa de uma nova concepção do espaço urbano a partir da análise do Movimento \#OcupeEstelita.

Para tanto, inicia-se com a análise do direito à cidade a partir da retomada das concepções de Henry Lefebvre. Após, apresenta-se as principais características e as possibilidades que o direito à cidade gera enquanto força transformadora da realidade urbana. Em seguida, busca-se atualizar as concepções aos dias atuais, tomando as considerações de David Harvey como o principal guia nessa jornada, aproximando-o de nosso ordenamento jurídico.

Analisa-se, em seguida, a importante atuação coletiva na luta pelo direito à cidade, investigandose brevemente a teoria dos movimentos sociais a partir da teoria de Maria Gohn, James Jasper e outros teóricos, destacando-se algumas características importantes, assim como a relevância da atuação coletiva no cenário político interno e externo. Além disso, explora-se a atuação dos movimentos sociais urbanos ao longo dos tempos, ressaltando a articulação do movimento "Occuppy Wall Stret", que transformou a relação do cidadão com a cidade e a política.

Por fim, analisa-se com especial atenção a trajetória do Movimento \#OcupeEstelita, da cidade de Recife-PE, que há anos luta pela concretização do direito à cidade e a materialização da utopia, isto é, uma nova forma de vida em sociedade. Além disso, com o auxílio de pesquisadores locais, como Érico Andrade Oliveira, investiga-se o modo de atuação e o processo de surgimento do movimento, explorando ainda as contradições do modelo de desenvolvimento adotado pela capital pernambucana.

\section{0 direito à cidade: de Lefebvre aos dias atuais}

O termo direito à cidade surge com o filosofo marxista e sociólogo francês Henry Lefebvre, na obra intitulada "Le droit à la ville", publicada nos primeiros meses de 1968. Em seu escrito, que ainda mantém assustadora atualidade, o autor procura analisar de forma dialética as complexidades do espaço urbano, rejeitando a postura determinista e reinante no urbanismo modernista.

O modo de produção e reprodução do espaço urbano, que devastava a vida cotidiana, era o que despertava a crítica de Lefebvre. Antes concebida como espaço de encontro e descoberta, a cidade assumia cada vez mais a forma de mercadoria, mero espaço destinado à produção do lucro, convertendo o habitante da cidade em objeto do espaço social. 
Conforme lembra Harvey (2014, p. 31-37), a reificação do espaço urbano é um projeto que remonta a subida ao poder de Luis Bonaparte, em 1851. Ele se inicia com a reformulação da estrutura urbana de Paris, concebida por Georges-Eugène Haussmann, a fim de resolver o problema do capital excedente e do desemprego. O êxito alcançado criaria um novo estilo de vida na capital francesa e salvaria a economia - ao menos por cerca de quinze anos, antes do desmoronamento do sistema financeiro especulativo e a estrutura de crédito em que seu modelo estava alicerçado.

Ao contrário de outros teóricos marxistas à época, Lefebvre procurava compreender a cidade em sua totalidade, não a resumindo a um simples "pano de fundo dos conflitos entre as forças produtivas e as relações de produção". Segundo o autor francês, o espaço urbano deve ser entendido como elemento configurador central da sociedade humana na modernidade, pois é daí que decorrem e se realizam as relações entre as pessoas, e não apenas como "resultado ou subproduto da industrialização" (TAVOLARI, 2016, p. 95).

Sendo assim, Lefebvre (2001) reclama o "direito à cidade" como a renovação desse elemento configurador da sociedade humana na tentativa de superar o processo de reificação/alienação reinante, de modo que os habitantes da cidade obtenham acesso à plenitude da vida em comunidade, que compreende a troca de experiências e vivências em comum, alargando o horizonte de emancipação humana. Criar ou reconstruir o ambiente urbano, a fim de que atenda e satisfaça seus habitantes, e não aos interesses do mercado, é o verdadeiro conteúdo do direito à cidade.

No entanto, Harvey (2014, p. 20) destaca que o direito à cidade é alvo de disputa e pode ser manuseado por diversos e distintos atores na sociedade, como financistas, empreiteiros e/ou os grupos subalternos, como os sem-teto, e tudo depende de quem Ihe conferirá significado. Sendo que, hoje, ele se encontra confinado nas mãos de poucos abastados pelo mundo, que integram uma pequena elite econômica e política, que conseguem transformar a cidade a seu bel-prazer. Por isso, exsurge a necessidade de a luta urbana dos subalternos assimilar e reivindicar o direito à cidade para si.

Nesse sentido, essa disputa não deve ser travada na tentativa de retomar o, agora, saudoso passado. A reivindicação do direito à cidade, em Lefebvre (2001), deve levar à construção de um novo urbanismo, atento aos anseios de seus cidadãos, e não às vontades do capital. Vejamos:

Impossível considerar a hipótese da reconstituição da cidade antiga; possível apenas encarar a construção de uma nova cidade, sobre novas bases, numa outra escala, em outras condições, numa outra sociedade. Nem retorno (para a cidade tradicional), nem fuga para a frente, para a aglomeração colossal e informe - esta é a prescrição. Por outras palavras, no que diz respeito à cidade, o objeto da ciência não está determinado. O passado, o presente, o possível não se separa (LEFEBVRE, 2001, p. 106).

Como se denota, o direito à cidade, proposto por Lefebvre, possui uma dimensão utópica de vida em sociedade. Em oposição à lógica mercantilizada de produção do espaço, o autor francês apregoa o direito à cidade como a prioridade do valor de uso sobre o valor de troca na experiência de vida urbana dos cidadãos, de modo que possam ser os condutores do próprio processo de desenvolvimento e descoberta.

Ademais, convém destacar que direito à cidade não pode ser confundido nem reduzido às demandas por moradia digna, tão comuns no noticiário brasileiro. Enquanto o direito à cidade é orientador de uma nova sociedade, edificada na noção de convivência entre os cidadãos, a demanda por moradia digna não contempla, necessariamente, esse caráter emancipador. Obviamente, as demandas por moradias ajudam a construir um horizonte político mais justo e digno, transformando a organização do espaço urbano, mas é preciso destacar que o direito à cidade vai além, buscando a edificação de algo novo. Conforme destaca Harvey (2013, p. 33):

O direito à cidade [...] não é apenas um direito condicional de acesso àquilo que já existe, mas sim um direito ativo de fazer a cidade diferente, de formá-la mais de acordo com nossas necessidades coletivas (por assim dizer), definir uma maneira alternativa de simplesmente ser humano. Se nosso mundo urbano foi imaginado e feito, então ele pode ser reimaginado e refeito. 
No entanto, as formulações filosóficas e sociológicas de Lefebvre não foram o suficiente para conter o avanço do capital financeiro sobre as cidades e da mercantilização da vida humana, por isso é preciso atualizar o conceito de direito à cidade, moldando-o à nossa realidade política e econômica, além de adequar a utopia à realidade. Conforme destaca Edésio Fernandes (apud VON GEHLEN, 2015, p. 242):

\begin{abstract}
O fato é que o conceito de 'direito à cidade' de Henri Lefebvre foi muito mais uma plataforma políticofilosófica e não explorava diretamente como, ou em que medida, a ordem legal que determinava o padrão excludente de desenvolvimento urbano. Aos argumentos sociopolíticos de Lefebvre, deve ser acrescentada uma outra linha, ou seja, argumentos jurídicos que nos permitam construir uma crítica à ordem legal não apenas na perspectiva de valores sociopolíticos ou humanitários, mas desde dentro da própria ordem legal.
\end{abstract}

Conforme destaca o autor, é necessário acrescentar argumentos jurídicos às ideias de Lefebvre, pois o ordenamento jurídico sempre esteve regulando e legitimando as relações que efetivamente incidem em nosso espaço urbano.

Nesse sentido, convém ressaltar o empenho empreendido por diversos agentes coletivos para elaboração da Carta Mundial pelo Direito à Cidade, elaborada a partir de diversos Fóruns Sociais pelo mundo, cujo maior objetivo é a gestão democrática das cidades. Na Carta, observa-se a indicação de três princípios básicos para a materialização do direito à cidade, a saber: 1) princípio do exercício pleno da cidadania; 2) da gestão democrática da cidade; 3) da função social da propriedade e da cidade.

Do mesmo, buscando entrelaçar o conceito de Lefebvre ao arcabouço jurídico, destaca-se a promulgação no Brasil do Estatuto das Cidades (Lei 10.257 de 10 de julho de 2001), editado para regulamentar os artigos 182 e 183 da Constituição da República, e considerado internacionalmente um exemplo no planejamento da política urbana. Em linhas gerais, pode-se dizer que o Estatuto da Cidade busca garantir o pleno desenvolvimento das funções sociais da propriedade e a garantia do bem-estar coletivo dos habitantes.

É a partir desse diploma, por exemplo, que se tem o estabelecimento da "cidade sustentável" como "direito difuso, transindividual e indisponível dos seus habitantes", além de outras disposições, como a regulação do uso da propriedade urbana, que ajudam a materialização do direito à cidade, antes tido apenas como utopia. Não obstante, lembram Uvo e Bodner (2015, p. 20), o Estatuo da Cidade "materializa um conjunto de conquistas históricas, fruto de lutas e articulações de diversos movimentos sociais e organizações populares que tinham como pauta a reforma urbana".

\title{
3 Os movimentos sociais e o direito à cidade
}

A concepção liberal-individualista da cidadania, oriunda das revoluções liberais do final do século XVIII, mostra-se cada vez mais obsoleta e incapaz de atender às aspirações da vida moderna em sociedade. Se antes a simples participação em eleições regulares e a não intromissão do Estado na vida particular era o bastante, hoje a atual concepção de cidadania reclama como primordial a intensa participação dos cidadãos no cenário político, a fim de que sejam os atores principais do próprio processo de desenvolvimento, bem como o respeito e a promoção de direitos.

A intensa participação política dos cidadãos no cenário político, importante medida de transformação e aperfeiçoamento da realidade político-social, é potencializada e fortalecida com a atuação dos movimentos sociais, sobretudo quando a pauta em questão é o direito à cidade e a temática urbana. Fugindo do paradigma liberal, os movimentos sociais ampliam o leque de possibilidade de atuação do cidadão.

Formados em torno de objetivos e causas comuns, sendo em sua maioria associadas a questões sociais, políticas, econômicas e/ou culturais, os movimentos sociais são, conforme ensina Jasper (2016, p. 23), "esforços persistentes e intencionais para promover ou obstruir mudanças jurídicas e sociais de longo alcance, basicamente fora dos canais institucionais normais sancionados pelas autoridades", que buscam persuadir os demais cidadãos da necessidade de mudança/manutenção do "status quo". Do mesmo modo, Gohn (2004, p. 141) ressalta que os movimentos sociais se manifestam "como ações sociais coletivas de 
caráter sociopolítico e cultural que viabilizam distintas formas da população se organizar e expressar suas demandas".

No entanto, conforme ressalta Touraine (1999, p. 13), é preciso cautela na hora de identificá-los, pois nem sempre ações coletivas que resultam em transformação/manutenção do "status quo" são resultado da ação de movimentos sociais. Desse modo, não podem ser confundidos com "grupos de interesses", que atuam por meio de lobby, ou ONGs, pois ambos são incapazes de representar ou criar novas identidades, conforme explica o sociólogo francês:

A noção de movimento social só é útil se permitir pôr em evidência a existência dum tipo muito particular de ação coletiva, aquele tipo pelo qual uma categoria social, sempre particular, questiona uma forma de dominação social, simultaneamente particular e geral, invocando contra ela valores e orientações gerais da sociedade, que ela partilha com seu adversário, para privar este de legitimidade.

Atuantes mesmo nos momentos mais delicados, como em meio a guerras e ditaduras, observam-se grandes contribuições dos movimentos sociais para a sociedade, ajudando a transformar a realidade social, mobilizando a sociedade a partir de protestos, ou práticas de pressão ao pequeno e restrito círculo oficial de poder, como indicam, por exemplo, os movimentos atuantes nos Estados Unidos da América pelos direitos civis e contra a guerra do Vietnã ocorridos na década de 60 do século passado, ou os diversos movimentos atuantes no Brasil contra a ditadura civil-militar, iniciada em 1964.

Nos dias atuais, a atuação dos movimentos sociais - que se distingue do passado, entre outras coisas, por novas formas de organização e pelo uso da internet - busca ampliar o horizonte de participação política, na tentativa de aperfeiçoar a democracia, e preocupa-se em construir sociedades democráticas, sustentáveis e plurais, com o reconhecimento da importância da identidade/diferença e da multicuturalidade, além da edificação de novos saberes.

Não por acaso, Gohn (2014, p. 46-47) sistematiza as abordagens teóricas sobre as ações coletivas dos movimentos sociais, neste milênio, ao redor de alguns eixos básicos, a saber: 1) "os novos requerimentos da modernidade e redefinição do sujeito racional de forma a incorporar as identidades culturais"; 2) "a busca de um sujeito que articule o global com o local"; 3) "a democracia e suas formas", com especial ênfase a democracia participativa e deliberativa, e "as formas de resistências comunais".

Dentre as abordagens que analisam ações coletivas que discutem a "democracia e suas formas", merecem destaque aquelas centradas nas atuações dos movimentos sociais, que perseguem a apropriação e a transformação do espaço urbano pelos habitantes da cidade, pois revitalizam a perspectiva de gestão do bem comum, apostando no caráter participativo, além de mostrar também a vitalidade do conceito de direito à cidade, em busca da construção da utopia de uma nova cidade, proclamada por Lefebvre.

Vale ressaltar, todavia, que a luta coletiva em razão da temática urbana não é nova, embora tenha recebido nova roupagem nos tempos atuais a partir da obra de Lefevbre. Nesse sentido, destaca-se que a luta por moradia digna, ou por condições adequadas de se viver, o que inclui protestos contra a reforma urbana autoritária, é antiga e, no Brasil, remonta ao início do século XX, como no caso da "Revolta da Vacina", em 1904.

Ainda que o estopim tenha sido, de fato, a implementação da vacinação obrigatória na população fluminense pelo então presidente da república, Rodrigo Alves, a revolta também englobava a insatisfação popular contra a reforma urbana da cidade do Rio de Janeiro e o autoritarismo empregado na demolição de cortiços, que implicava na remoção de famílias pobres para a periferia da cidade.

Assim como no exemplo citado, o país assistiu diversas ações coletivas eclodirem colocando o urbano em pauta, sobretudo no final do último século, com diversas reinvenções por moradia e pela transformação do espaço urbano. O inchaço das grandes cidades brasileiras, em decorrência da migração da população campesina, fez surgir realidades caóticas nas metrópoles. Em razão disso, importantes movimentos sociais urbanos surgem contestando a lógica político-territorial brasileira, responsável por deixar milhões de pessoas em condições precárias, ou, até mesmo, sem moradia. 
Nesse sentido, destaca-se a atuação da União Nacional por Moradia Popular (UNMP) e do Movimento Nacional de Luta por Moradia (MNLM), que surgem no final da década de 80 do século passado, com o objetivo de contestar a lógica excludente de nossas cidades. Outro que merece destaque é o Movimento dos Trabalhadores Sem Teto (MTST), que por meio de ações contestatórias de grande impacto, como grandes passeatas, bloqueio de ruas e ocupação de terrenos e casas ociosas, busca pressionar o poder público e chamar a atenção de toda a sociedade ao problema urbano, a fim de que o acesso à moradia digna não seja mais compreendido como mercadoria, mas como direito fundamental, assegurado pela Constituição da República, como determina o seu artigo $6^{\circ}$.

No entanto, conforme alerta Rolnik (2015, p. 26), o fenômeno da precarização da vida urbana não é especificidade brasileira, mas global, atingindo países ricos e pobres, e resultado do "processo de desconstrução da habitação como bem social e de sua transmutação em mercadoria e ativo financeiro", afetando o exercício do direito à moradia digna ao deixar grandes populações, sobretudo a de baixo poder aquisitivo, à mingua.

Mesmo em meio a essas dificuldades, a temática urbana e, sobretudo, o direito à cidade, ganham destaque mundial nesta década com o surgimento do movimento iniciado no centro financeiro de Manhattan, nos Estados Unidos da América, o Occupy Wall Stret. Ainda que a pauta inicial do movimento, iniciado em 17 de setembro de 2011, não fosse especificamente o direito à cidade, mas diversas demandas contra a desigualdade econômica e os efeitos da crise financeira, os protestos conseguiram trazer uma nova perspectiva de relacionamento entre o cidadão e a cidade, além da concepção de uma nova sociedade, com a prioridade do valor de uso sobre o de troca, conforme os termos lefebvrianos.

Acampados no parque Zuccotti, em meio ao maior centro financeiro do mundo, os manifestantes denunciavam a perversidade do sistema econômico e, ao mesmo tempo, reivindicavam o direito ao espaço público. Seguindo os exemplos vindos do movimento espanhol "15M" (também conhecido como "Indignados") e dos protestos que abalaram o mundo na Primavera Árabe, o Occupy Wall Stret (OWS) organizava-se de maneira descentralizada, através de assembleias, utilizando o espaço urbano como estratégia de luta e como palco do florescimento de uma democracia participativa.

A estratégia de "ocupar" o espaço público repercutiu em diversas cidades dos Estados Unidos da América e ganhou o mundo, demonstrando a vitalidade da estratégia. Mesmo que todas as demandas não tenham sido atendidas, devido também à multiplicidade de demandas do movimento, o OWS obteve uma série de pequenas vitórias (como a influência nas eleições que ocorreram no ano seguinte) e, como principal legado, o lampejo de uma sociedade mais participativa através da atuação dos movimentos sociais. Sobre o movimento, Harvey (2014, p. 80-81) é enfático:

Em Wall Street a 'rua' está sendo ocupada - horror dos horrores - por outros! Espalhando-se de uma cidade a outra, as táticas do Occupy Wall Street consistem em ocupar um espaço público central, como um parque ou uma praça, perto dos quais se concentrem muitas alavancas do poder e, ao colocar corpos humanos nesse lugar, transformar espaço público em comuns políticos - um lugar para debates e discussões abertas sobre o que esse poder está fazendo e qual seria a melhor maneira de se opor a ele. Essa tática, notavelmente reativa nas nobres e atuais lutas que se travam na Praça Tahir, no Cairo, espalhou-se pelo mundo inteiro (Puerta do Sol, em Madri, Praça Sintagma, em Atenas, e agora nas escadarias da Catedral de São Paulo, em Londres e na própria Wall Street). Isso nos mostra que o poder coletivo dos corpos no espaço público ainda é o instrumento mais eficaz de oposição quando todos os outros meios de acesso encontram-se bloqueados.

A possibilidade de uma sociedade com maior participação do cidadão na gestão da coisa pública, objetivo de diversos dos movimentos sociais urbanos, permite que a cidade se transforme no local de realização do ser humano, assegurando o bem-estar coletivo e o florescimento de uma urbanização que privilegia as pessoas. As ações coletivas dos movimentos sociais, para muito além dos preconceitos clichês, abre um importante canal de diálogo com o poder público e fortalece as demandas dos cidadãos.

Nesse sentido, convém destacar os protestos ocorridos na Turquia, em 2013. Na ocasião, uma ação coletiva de mais de 50 ecologistas buscava proteger o parque Taskim Gaze, importante área verde da cidade 
de Istambul, que seria derrubado para a construção de um imponente empreendimento comercial. Contrário ao modelo que privilegia o desenvolvimento econômico em detrimento de outros valores importantes, como a preservação ambiental, o grupo ocupou o parque e resistiu à ferocidade da polícia turca, fazendo florescer um grande e espontâneo movimento de massas que, ao final, conseguiu cancelar a derrubada do parque, ocupando a área.

Com respeito à sublevação do povo turco contra as medidas governamentais, não obstante, Raquel Rolnik (2015, p. 375) afirma que ela transcende a questão ecológica: "a defesa do parque Gaze expressa muito mais que o protesto contra o corte de algumas árvores: é a demanda pela manutenção do caráter público do espaço urbano e de sua diversidade, em oposição à sua mercantilização". Além disso, a relatora especial da ONU pelo Direito à Moradia Digna também destaca que "trata-se de insurgência contra a política do ex-primeiro-ministro e atual presidente Recep Tayyip Erdogan, centrada em grandes projetos imobiliários e remoções em massa, e também contra as formas autoritárias de decisão que estão por trás dessas ações" (ROLNIK, 2015, p. 375).

Assim como no exemplo turco, em que o bem-estar coletivo era colocado acima dos interesses econômicos pelos manifestantes, diversos movimentos sociais brasileiros agitam a vida pública do país propondo uma relação diferente com a cidade. Além das demandas típicas por moradia digna, que efetivamente auxiliam o projeto de inclusão social, há também movimentos que reivindicam a cidade como espaço de realização do ser humano, baseada na plena sociabilidade entre seus habitantes, isto é, a materialização do direito à cidade, que não se encerra obviamente no acesso à moradia digna.

O Movimento Passe Livre (MPL), por exemplo, é um desses movimentos sociais. Fundado em 2005, no Fórum Social Mundial de Porto Alegre, o movimento busca pôr fim à lógica excludente do transporte público. A "tarifa zero", principal pauta do MPL, é entendida como o arranjo capaz de criar uma cidade mais democrática. Organizado de maneira descentralizada, o movimento é responsável por abrir a caixa de pandora da política em 2013, ao articular as manifestações contra o aumento da passagem que, posteriormente, ganhariam as ruas de todo o país. Suas manifestações e reinvindicações deixam claro que o propósito do movimento vai muito além do transporte público, buscando criar uma nova ideia de cidade:

A organização descentralizada da luta é um ensaio para uma outra organização do transporte, da cidade e de toda sociedade. Vivenciou-se, nos mais variados cantos do país, a prática concreta da gestão popular. Em São Paulo, as manifestações que explodiram de norte a sul, leste a oeste, superam qualquer possibilidade de controle, ao mesmo tempo que transformaram a cidade como um todo em um caldeirão de experiências sociais autônomas. A ação direta dos trabalhadores sobre o espaço urbano, o transporte, o cotidiano da cidade e de sua própria vida não pode ser apenas uma meta distante a ser atingida, mas uma construção diária nas atividades e mobilizações, nos debates e discussões. O caminho se confunde com esse próprio caminhar (MOVIMENTO PASSE LIVRE SÃO PAULO, 2013, p. 17-18).

Assim como o MPL, outros movimentos organizam-se em razão do direito à cidade, buscando criar uma nova perspectiva para a vida urbana. A apropriação e transformação democrática do espaço pelos habitantes da cidade, assim como a garantia e acesso aos direitos básicos para uma vida digna, é potencializada pela atuação dos movimentos sociais, indispensáveis para a vida pública e para a materialização do direito à cidade, como se verá adiante na análise do Movimento \#OcupeEstelita.

\section{Movimento \#OcupeEstelita: a luta pelo direito à cidade}

Com 101.7 mil metros quadrados, o Cais José Estelita está inserido em uma área bastante valorizada de Recife, entre o bairro de São José e o do Cabanga, e está em meio a duas grandes avenidas, abrigando o segundo pátio ferroviário mais antigo do país e velhos armazéns de açúcar. Localizado em frente à Bacia do Pina, que assegura uma das mais belas vistas da cidade, o local representa os tempos áureos do transporte ferroviário do país, tendo sido um importante entreposto comercial brasileiro. 
No entanto, o descaso (proposital ou não) de vários anos da União, responsável legal pela área após a dissolução da Rede Ferroviária Federal S/A - RFFSA, deixou o Cais José Estelita em ruínas. Em razão disso, sem antes discutir o futuro do local com os associações e moradores da cidade, a área foi colocada em leilão no ano de 2008, através da Portaria $n^{\circ} 282$, de 21.09.2007, sendo arrematada pelo consórcio intitulado "Novo Recife", composto por grandes empresas da construção civil (FIGUEIREDO, 2015, p. 99-108).

Para a área, o consórcio desenvolveu um projeto arquitetônico que inclui um complexo empresarial, comercial, hoteleiro e residencial de luxo, com a previsão de construção de doze torres, de até 40 pavimentos cada, apresentado em audiência na Câmara Municipal de Recife, em março de 2012, com o mesmo nome do consórcio (SOUSA, 2014, p. 161). Distanciando-se das características urbanas e históricas do local em que se insere, o projeto "Novo Recife" alicerça-se no discurso de renovação do bairro para, no entanto, reproduzir a mesma lógica excludente que marca a arquitetura brasileira atualmente, isto é, o desenvolvimento do espaço urbano como negação dos espaços comuns e públicos de convivência.

Como resposta, após a apresentação do projeto à câmara, diversos ativistas se unem para ampliar a discussão sobre o planejamento urbano de Recife e debaterem alternativas para o Cais José Estelita, gerando o movimento social "Direitos Urbanos" (DU), gerido de maneira horizontal e criado para discutir questões relativas "à mobilidade, lazer, áreas de convivência, uso do solo e demais temas ligados ao urbanismo de modo geral" (OLIVEIRA, 2014a, p. 1).

Assim, na esteira dos movimentos sociais internacionais que ocupam o espaço como estratégia e reivindicam uma nova realidade político-social pautada no bem-estar coletivo, deu-se início as ocupações do Cais, o "\#OcupeEstelita". No dia 15 de abril de 2012, a partir de uma organização descentralizada e apartidária, a área foi ocupada por centenas de cidadãos, que puderam compartilhar cultura e conhecimento em uma grande festa pelo direito à cidade, materializando a utopia do possível. A ação ainda seria repetida nos dias 22 de abril e 12 de maio do mesmo ano, abrindo o caminho de ocupações que seriam realizadas em anos posteriores (SOUSA, 2014, p. 92).

Apesar do envolvimento da população recifense, o projeto fora aprovado no Conselho de Desenvolvimento Urbano (CDU), órgão municipal criado para gerir a questão urbana de Recife, em uma sessão eivada de polêmicas e controvérsias, no final de 2012. No entanto, além da discussão do projeto nas ruas pelos coletivos, a questão fora judicializada por uma série de ações judiciais, que questionam de maneira direta o projeto.

Destaca-se, nesse sentido, a Ação Civil Pública proposta pelo Ministério Público de Pernambuco (processada sob o n. 0195410-25.2012.8.17.001), em 19 de dezembro de 2012, responsável por questionar uma série de irregularidades, como a não intervenção de órgãos técnicos, tais como o IPHAN, ANTT e DNIT, e a ausência de estudo de impacto de vizinhança e de impacto ambiental; bem como a Ação Civil Pública proposta pelo Ministério Público Federal (processada sob o n. 0001291-34.2013.4.05.8300), em 06 fevereiro de 2013, requerendo estudos técnicos dos órgãos competentes, a não edificação do local pelo consórcio e a nulidade do leilão realizado, além de outros itens; afora outras três Ações Populares discutindo irregularidades na aprovação do projeto no Conselho de Desenvolvimento Urbano (CDU), também propostas no final de 2012, por membros do movimento Direitos Urbanos (DU).

Convém ressaltar, por oportuno, que assim como em outras cidades pelo Brasil e o mundo, o planejamento urbano da capital pernambucana vai sendo definido única e exclusivamente pelos interesses do mercado imobiliário, que pouco (ou nada) se importa com as memórias da cidade. Distanciando-se de suas raízes, Recife adota uma política urbana fragmentada, de isolamento, renunciando ao projeto de uma cidade como possibilidade de convivência e descoberta entre cidadãos.

Não obstante essas questões, o "Novo Recife" seguiu adiante, após superar as liminares das ações judiciais que impediam o avanço do projeto, e conquistou importantes e contestadas vitórias, como a aprovação em âmbito municipal das novas "compensações e mitigações" pelo empreendimento a ser construído, no final do ano de 2013, que asseguram uma série de medidas para integrar a obra à comunidade.

A reviravolta do caso, no entanto, ocorre em 21 de maio de 2014, quando o consórcio obtém autorização da Prefeitura Municipal de Recife para a demolição dos antigos galpões de açúcar, antes mesmo do término 
dos estudos em andamento pelos órgãos competentes determinados em juízo. Na mesma noite, inicia-se a derrubada das antigas estruturas do Cais.

Contudo, a demolição é freada pela ação organizada de membros do movimento Direitos Urbanos e da população em geral. A filmagem, por parte de um integrante do movimento, e o posterior compartilhamento das imagens da derrubada dos galpões são os estopins do levante popular. De imediato, vários cidadãos sem vinculação político partidária, ou adesão à movimentos sociais, e ativistas do Direitos Urbanos comparecem ao local para impedir o início das obras, enfrentando a truculência de seguranças particulares. Naquele momento, de forma espontânea, iniciava-se o movimento pela ocupação do local, a fim de defendê-lo (OLIVEIRA, 2015, p. 141-142).

Mesmo com o silêncio da imprensa pernambucana, o movimento ganhava cada vez mais atenção e adesão, fazendo cessar a demolição. De forma autônoma, descentralizada e horizontal, a luta pelo direito à cidade era organizada no local, demonstrando que outra perspectiva para a política era possível. Resistindo às adversidades, o Movimento \#OcupeEstelita começava a frutificar, tanto que, no dia seguinte, o IPHAN embargou liminarmente o projeto (pelo prazo de 5 dias), buscando garantir a integridade do patrimônio histórico, dando combustível à ocupação que perduraria dali em diante. Nesse sentido, a respeito das possibilidades da ocupação, Oliveira (2014b, p. 110) destaca que:

\begin{abstract}
Ocupar o Cais Estelita é tomar posse da cidade não no sentido de se apropriar privadamente do espaço público, mas de exigir um modelo de urbanismo alternativo que passa, antes de tudo, pela participação popular nas decisões sobre o desenho urbano das cidades, que é constantemente sequestrado pelo poder onipotente do capital imobiliário e especulativo. Ocupar é exigir posse sobre as decisões da cidade e equilibrar a balança da democracia que invariavelmente pende para o poder do capital. A insurgência contra as decisões realizadas a portas fechadas por alguns políticos e que influenciam a vida de milhares de pessoas, que não conseguem, pelos meios institucionais, serem ouvidas, passa primeiramente pela denúncia da força do capital nessas decisões e, posteriormente, pela reivindicação por um processo tanto mais transparente quanto mais participativo.
\end{abstract}

Edificando uma nova ideia de política urbana, em que a cidade é compreendida como espaço de convivência, descoberta e sociabilidade, o Movimento \#OcupeEstelita (MOE) fortalecia-se cada dia mais, contando com o apoio e incentivo de diversos atores, congregando diversos movimentos e ideais em torno de um bem coletivo. Protagonizado e liderado, inicialmente, pelo movimento Direitos Urbanos, a partir do ano de 2012, o Movimento Ocupe Estelita ganhava vida própria, estabelecendo-se como um organismo novo na política recifense, com grande influência das redes sociais, e suas principais decisões eram adotadas por assembleias, em uma verdadeira experiência de democracia direta.

Além disso, durante a ocupação, o MOE fez florescer uma nova realidade cultural na cidade de Recife. Isto porque a ocupação era acompanhada de diversas atividades culturais, responsáveis por trazer e apresentar à população o Cais José Estelita, definitivamente uma nova expressão de resistência. Não obstante, destacam-se as diversas aulas públicas e debates realizados, intervenções artísticas e circenses, oficinas variadas e, com maior repercussão, os shows de importantes nomes da música popular brasileira, entre eles: Marcelo Janeci, Otto, Criolo e Karina Burh, responsáveis por levar milhares de pessoas ao local.

Em meio ao caos da capital pernambucana, o Cais renascia como espaço plural, coletivo e cultural. Nesse sentido, com relação à cultura, o sociólogo e professor Jasper (2016, p. 218) lembra que ela: "[...] nos ajuda a agir no mundo, assim como a entendê-lo. Nós nos relacionamos com nossos contextos sociais, psicológicos, físicos (e espirituais), em parte, imaginando nosso caminho em torno deles, usando como guias nossas emoções". É exatamente por isso que exsurge a necessidade de os movimentos assumirem e atuarem no âmbito cultural, pois eles: "nos ajudam a [...] tratarmos uns aos outros, de imaginarmos novos futuros, novas inspirações e esperanças, novos símbolos, personagens e outras sinalizações que podemos usar no caminho para o futuro".

Além da questão cultural, convém destacar que o objetivo do MOE não era a mera conservação das (abandonadas) estruturas existentes no local, mas a possibilidade de transformá-lo em local vivo, isto é, em local de convívio e troca de experiências entre os habitantes da cidade. Ao lutar por outra destinação 
ao Cais José Estelita, o MOE torna concreta a reivindicação do direito à cidade como possibilidade de uma nova vida social e da materialização da utopia, a partir de uma postura contra-hegemônica e de caráter emancipatório. Mesmo com obstáculos, o movimento obtinha vitórias importantes, como a revogação por parte da prefeitura municipal da autorização de demolição dos galpões do Cais.

No entanto, em decisão monocrática (ratificada pelo plenário posteriormente) contestada por membros do Ministério Público e integrantes do MOE, o Tribunal de Justiça de Pernambuco determinou a reintegração de posse do imóvel, facultando o uso da força policial caso fosse necessário. Assim, no dia 17 de junho de 2014, após exatos 29 dias do início da ocupação, a Polícia Militar do estado de Pernambuco desocupa o local, em uma ação seriamente criticada. Nesse sentido, as críticas apontavam o uso excessivo da força pelos militares, justamente em um dia em que as atenções estavam voltadas ao jogo da seleção brasileira na Copa do Mundo, e o descumprimento do acordo anteriormente firmado entre manifestantes, Ministério Público e consórcio "Novo Recife", no sentido de avisar antecipadamente eventual ação de reintegração de posse e garantir a pacificidade do ato.

Em resistência à ação truculenta de desocupação do local, os manifestantes logo ocuparam as imediações do Cais, armando acampamento sob viadutos vizinhos. Todavia, em razão de diversas adversidades como, sobretudo, a exposição à violência, a ocupação fora parcialmente desfeita no dia 29 de junho de 2014. No dia seguinte, no entanto, os manifestantes ocuparam o prédio da prefeitura municipal de Recife em protesto, exigindo reuniões e maior diálogo com o poder público, antes de saírem pacificamente do local no dia 01 de julho de 2014, após ordem de reintegração de posse.

Desde então, o Movimento \#OcupeEstelita segue na luta pela concretização do direito à cidade em Recife. Ainda que o ápice das reivindicações tenha sido alcançado com a ocupação iniciada em maio de 2014, na qual milhares de recifenses estiveram presentes, o movimento segue agitando a vida política da capital pernambucana, a partir de uma gestão descentralizada e horizontal, com o intenso uso das redes sociais para a organização dos atos de protesto e manifestações culturais, sempre atento ao desenrolar do projeto para o Cais.

O projeto "Novo Recife", por sua vez, também segue agitando a vida política de Recife, com inúmeras controvérsias, envolvendo Prefeitura Municipal, Ministério Público, construtoras, arquitetos, engenheiros, técnicos e ativistas. Nesse sentido, após a pressão da sociedade civil, o consórcio redefiniu o projeto, alegando, desse modo, integrar o "Novo Recife" ao entorno e satisfazer o interesse público ao construir no local praças, parques e ciclovias de uso público, destinando $65 \%$ da área ao uso público.

Em 04 de maio de 2015, o Plano Específico do Cais José Estelita, responsável por regulamentar as diretrizes de construção do local, fora aprovado e transformado em lei pela Câmara de Vereadores e a Prefeitura Municipal - mesmo com uma Ação Civil Pública protocolada pelo Ministério Público de Recife em 30 de abril de 2014, que apontava supostas falhas no Plano. Como resposta, um ato com mais de duas mil pessoas foi realizado pelo MOE nas ruas de Recife contestando a aprovação. Além disso, no dia 11 de maio de 2015, mais uma Ação Civil Pública fora proposta pelo Ministério Público de Pernambuco, dessa vez requerendo a nulidade da lei que aprovou o Plano Específico.

Não obstante, para demonstrar a complexidade do caso, em 30 de setembro de 2015 a Polícia Federal deflagrou operação para investigar possíveis fraudes no leilão ocorrido em 2008 , analisando possível subfaturamento do preço. Em 27 de novembro de 2015, o juiz da $1^{\text {a }}$ Vara da Justiça Federal em Pernambuco exarou sentença anulando o leilão, decisão que seria suspensa pelo Tribunal Regional Federal da $5^{\mathrm{a}}$ região (TRF-5) em 15 de dezembro de 2015. Com a decisão de anulação suspensa, o Conselho de Desenvolvimento Urbano (CDU) aprovou o projeto do novo Recife em sessão do dia 22 de dezembro de 2015, o que motivou mais uma Ação Civil Pública pelo Ministério Público de Pernambuco no início de 2016. Em novembro de 2017, o TRF5 decidiu reformar a sentença de $1^{\circ}$ grau que anulara o leilão, afirmando a legalidade do certame realizado. Desde então, o projeto segue parado, com estudos do IPHAN sobre o sítio arqueológico em que o Cais está localizado. 


\section{Conclusão}

A edificação de uma nova política urbana é um dos grandes desafios da contemporaneidade. Superar o modelo desenvolvimentista, que já demonstrou ser incapaz de compreender a cidade como espaço de convivência, descoberta e sociabilidade, não é uma tarefa simples, mas necessária para a construção de uma nova realidade social centrada no bem-estar coletivo das pessoas.

Retomar o conceito lefebvriano de direito à cidade e atualizá-lo aos nossos dias através de dispositivos jurídicos, portanto, torna-se medida de urgência a fim de contrapor a concepção mercadológica que pauta o urbanismo atualmente. Conforme anteriormente demonstrado, a obra de Henry Lefebvre pode ser lida como um projeto orientador de outra realidade político-urbana, contrária ao modelo segregacionista que hoje impera e, sobretudo, uma alternativa à postura determinista do urbanismo. Conceber o espaço urbano como local para satisfazer as necessidades e possibilidades coletivas é o grande legado do sociólogo francês.

Esse legado é potencializado e aperfeiçoado quando transformado em pauta dos movimentos sociais. Nos últimos anos, como se buscou construir, diversas ações coletivas agitaram a vida pública pela materialização do direito à cidade e a construção de uma nova sociedade, demonstrando a vitalidade do conceito, que não se encerra no mero acesso à moradia digna. Formados em torno de objetivos comuns, os movimentos sociais urbanos conseguem pressionar as instâncias de poder buscando "transformar as cidades em algo diferente", como diria Harvey (2014), a fim de que satisfaçam nossas necessidades humanas.

Em meio às dificuldades da vida contemporânea, que dia após dia assume uma feição mais individualista e reificante, os movimentos sociais agitam a esfera pública em busca de alterações no "status quo" jurídico, político ou social em favor da coletividade. Ampliando o horizonte de participação do cidadão, a articulação dos movimentos sociais nesta década representa uma nova forma de pensar o espaço urbano e a política, como demonstram as ações coletivas do Movimento Occuppy Wall Stret e do movimento turco.

No Brasil, o Movimento \#OcupeEstelita é protagonista na luta pelo direito à cidade nos últimos anos, e vem transformando a realidade político-social da capital pernambucana, buscando o florescimento de uma nova sociedade, pautada no bem-estar coletivo de seus cidadãos. Organizado de maneira descentraliza e horizontal, o movimento é como voz ativa em um delicado debate: o futuro do Cais José Estelita e, por consequência, o da cidade de Recife.

Contrapondo-se ao ideal desenvolvimentista, o Movimento \#OcupeEstelita não busca a transformação do Cais José Estelita em local de descoberta, de convívio entre os habitantes, conservando parte importante da memória da cidade. Para tanto, enfrenta os interesses de grandes construtoras e o da velha política, que aponta a construção do projeto "Novo Recife" a única solução contra o abandono da área.

No entanto, o movimento vem superando esses desafios e, com o auxílio da arte, demonstrando que outra realidade é possível para o Cais José Estelita. Ocupando e transformando o espaço urbano, o Movimento \#OcupeEstelita materializa a utopia do direito à cidade.

\section{Referências}

CARTA MUNDIAL PELO DIREITO À CIDADE. Disponível em: <http://normativos.confea.org.br/ downloads/anexo/1108-10.pdf>. Acesso em: 10 jan. 2017.

FIGUEIREDO, Carolina Dantas. Ocupe como Utopia: Um ensaio sobre a noção de rede e o Caso Estelita. Revista Esferas, Brasília, v. 1, p. 99-108, 2015. Disponível em: <https://portalrevistas.ucb.br/ index.php/esf/article/view/5783>. Acesso em: 10 jan. 2017.

GOHN, Maria da Glória. Teorias dos movimentos sociais na contemporaneidade. In: GOHN, Maria da Glória (Org.). Movimentos sociais na era global. 2. ed. Petrópolis: Vozes, 2014. v. 1. p. 19-36.

GOHN, Maria da Glória. Novas teorias dos movimentos sociais. 5. ed. São Paulo: Edições Loyola, 2014. 
GOHN, Maria da Glória. Movimentos Sociais na Contemporaneidade. Revista Brasileira de Educação, Rio de Janeiro, v. 16, p. 333-361, 2011. Disponível em: <http://www.scielo.br/pdf/rbedu/v16n47/ v16n47a05.pdf>. Acesso em: 07 jan. 2017.

HARVEY, David. Cidades Rebeldes: do direito à cidade à revolução urbana. São Paulo: Martins Fontes, 2014.

HARVEY, David. A liberdade da cidade. In: MARICATO, Ermínia et al. (Org.). Cidades rebeldes: passe livre as manifestações que tomaram as ruas do Brasil. São Paulo: Boitempo; Carta Maior, 2013. p. 2734.

JASPER, James M. Protesto: uma introdução aos movimentos sociais. Rio de Janeiro: Zahar, 2016.

LEFEBVRE, Henry. $O$ direito à cidade. São Paulo: Centauro, 2001.

LEFEBVRE, Henry. A revolução urbana. Belo Horizonte: UFMG, 2002.

LUCAS, Doglas Cesar. A desobediência civil e os novos movimentos sociais: a construção democrática do direito. 2001. 151 p. Dissertação (Mestrado em Direito). Universidade Federal de Santa Catarina. Florianópolis, 2001. Disponível em: <https://repositorio.ufsc.br/bitstream/ handle/123456789/79630/182048.pdf?sequence=1>. Acesso em: 12 jan. 2016.

MATOS, Andityas Soares de Moura Costa; SOUZA, Joyce Karine de Sá. A desobediência civil e os movimentos populares egípcios do século XXI. Revista da Faculdade de Direito da Universidade Federal de Minas Gerais, Belo Horizonte, n. 61, p. 21-56, jul./dez. 2012. Disponível em: <http://www. direito.ufmg.br/revista/index.php/revista/article/view/P.03042340201261p21>. Acesso em: 12 jun. 2015.

MATOS, Olgaria C. F. Paris 1968: As barricadas do desejo. São Paulo: Brasiliense, 1989.

MINHOTO, Laurindo Dias. Nota crítica sobre a teoria dos sistemas, o neoliberalismo e o direito à cidade. Revista Direito e Práxis, Rio de Janeiro, v. 5, p. 462-474, 2014. Disponível em: <http://www.epublicacoes.uerj.br/index.php/revistaceaju/article/view/13741>. Acesso em: 14 jan. 2017.

MOVIMENTO PASSE LIVRE - SÃO PAULO. Não começou em Salvador, não vai terminar em São Paulo. In: MARICATO, Ermínia et al. (Org.). Cidades rebeldes: passe livre as manifestações que tomaram as ruas do Brasil. São Paulo: Boitempo: Carta Maior, 2013. p. 13-18.

OLIVEIRA, Érico Andrade Marques de; LINS, Liane Cirne; LEMOS, Frida. Nem solidárias, nem rebeldes: a luta pelo direito à cidade para e pelas pessoas - o caso do \#OcupeEstelita. In: MORAES, Alana et al. (Org.). Junho: potência das ruas e das redes. São Paulo: Friedrich Ebert Stiftung, 2015. p. 135-156.

OLIVEIRA, Érico Andrade Marques de. Direitos urbanos: a luta em rede. Revista Coletiva, Recife, v. 11, p. 10, 2014a.

OLIVEIRA, Érico Andrade Marques de. Ocupe Estelita: as novas formas de atuação política. Insight Inteligência, Rio de Janeiro, ano XVII, n. 66, p. 108-113, 2014b. Disponível em: <http://www. insightinteligencia.com.br/66/PDFs/pdf9.pdf>. Acesso em: 15 jan. 2017.

PEREIRA, Tatiana Dahmer. Sísifo e sua pedra - Reflexões sobre o "direito à cidade" no Brasil em tempos de financeirização. Direito da Cidade, Rio de Janeiro, v. 8, p. 1137-1156, 2016. Disponível em: <http:// www.e-publicacoes.uerj.br/index.php/rdc/article/view/22537>. Acesso em: 15 jan. 2017.

REISDORFER, Guilherme Fredherico Dias. Definição e concretização do direito à cidade: entre direitos e deveres fundamentais. Revista de Direito Administrativo Contemporâneo, São Paulo, v. 19, p. 177197, 2015.

RODRIGUES, Arlete Moysés. A cidade como direito. Scripta - Nova Revista Electrónica de Geografía y Ciencias Sociales, Barcelona: Universidad de Barcelona, v. XI, n. 245, ago. 2007. Disponível em: <http:// www.ub.es/geocrit/sn/sn-24533.htm>. Acesso em: 07 jan. 2017.

ROLNIK, Raquel. Guerra dos lugares: a colonização da terra e da moradia na era das finanças. São Paulo: Boitempo, 2015. 
TAVOLARI, Bianca. Direito à cidade: uma trajetória conceitual. Novos Estudos CEBRAP, São Paulo, v. 104, p. 93-109, 2016. Disponível em: <http://novosestudos.uol.com.br/v1/contents/view/1624>. Acesso em: 05 jan. 2017.

TEIXEIRA, João Paulo Allain; AZEVEDO, A. P. S. Entre o uno e o plural: Breves considerações sobre poder constituinte e direito de resistência a partir do caso do Movimento Ocupe Estelita. In: VERONESE, Alexandre; SOARES, Fabiana de Menezes; SILVEIRA Vladmir Oliveira da (Org.). Direitos humanos e efetividade: Fundamentação e processos participativos. Florianópolis: CONPEDI, 2015.v. 1, p. 3-32.

TONUCCI FILHO, João Bosco Moura. O direito à cidade na urbanização planetária, ou: Henri Lefebvre por uma nova cidadania urbana. In: COSTA, Geraldo M. et al. (Org.). Teorias e práticas urbanas: condições para a sociedade urbana. Belo Horizonte: C/Arte, 2015. p. 215-230.

TOURAINE, Alain. Podemos viver juntos? Iguais e diferentes. Rio de Janeiro: Petrópolis, 1999.

VON GEHLEN, Jauro Sabino. O direito à cidade no Brasil. In: SALEME, Edson Ricardo et al. (Org.). Direito urbanístico, cidade e alteridade. Florianópolis: CONPEDI, 2015. v.1. p. 235-253. Disponível em: <http://www.conpedi.org.br/publicacoes/y0ii48h0/929a805v/rfrl7elRetD5XCuy.pdf>. Acesso em: 17 jan. 2017.

UVO, R. T.; BODNAR, Z. A epistemologia interdisciplinar do Direito à Cidade. In: SELEME, Edson Ricardo et al. (Org.). Direito urbanístico, cidade e alteridade. Florianópolis: CONPEDI, 2015. v. 1. p. 11-27. Disponível em: <http://www.conpedi.org.br/publicacoes/66fsl345/mq42p84j/0EtQhOFE475GLDAQ. pdf>. Acesso em: 10 jan. 2017.

Recebido em: 05/05/2017

Aprovado em: 04/05/2018 